Cite this: Phys. Chem. Chem. Phys., 2013, 15, 20600

Received 4th September 2013, Accepted 14th October 2013

DOI: $10.1039 / \mathrm{c} 3 \mathrm{cp} 53756 \mathrm{k}$

www.rsc.org/pccp

\title{
Heteroaromaticity approached by charge density investigations and electronic structure calculations $\dagger$
}

\author{
Jakob Hey, ${ }^{a}$ Dirk Leusser, ${ }^{a}$ Daniel Kratzert, ${ }^{a}$ Heike Fliegl, ${ }^{b}$ Johannes M. Dieterich, ${ }^{c}$ \\ Ricardo A. Mata*c and Dietmar Stalke*c
}

\begin{abstract}
In this paper we present the results of a high-resolution single crystal X-ray diffraction experiment at $15 \mathrm{~K}$ on a benzothiazol-substituted phosphane and a subsequent charge density study based on multipole refinement and a topological analysis according to Bader's quantum theory of atoms in molecules. Although two valence shell charge concentrations (VSCCS) in the non-bonding region of each phosphorus and sulfur atom were found, the integration of both heteroatomic basins emphasizes charge depletion. Nevertheless they are attractive for $\mathrm{C}-\mathrm{H} \ldots \mathrm{P}$ and $\mathrm{C}-\mathrm{H} \ldots \mathrm{S}$ hydrogen bonding in the solid state. The nature of the $\mathrm{P}-\mathrm{C}$ bonds and the question of aromaticity in the heterocycles were subject to our investigations. The ellipticities along the bonds were analysed to approach delocalization. The source function is employed to visualise atomic contributions to aromaticity. Theoretical calculations have been carried out to compute nuclear chemical shifts, induced ring currents and a variety of delocalization indices. All applied measures for delocalization point in the same direction: while heteroaromaticity is present in the benzothiazolyl substituents, the bridging $\mathrm{P}-\mathrm{C}$ bonds are only involved marginally, almost preventing total conjugation of the phosphane. The charge density distributions around the phosphorus and the sulfur atoms have very similar features but turn out to be chemically very different from each other. Commonly used simplifying concepts have difficulties in providing a comprehensive view on the electronic situation in the molecule. Our results raise doubts on the validity of the common interpretation of VSCCS as one-to-one representations of Lewis lone pairs.
\end{abstract}

\section{Introduction}

Aromaticity is one of the most fundamental concepts in chemistry. It was first established to explain the unusual stability and unique reactivity that was observed in benzenoid chemistry, and its validity has been expanded to innumerable further examples. The quantification of aromaticity is a large and vigorously discussed field of research, and different methods for the validation of the degree of aromaticity are still under development. ${ }^{1}$

In our current work on ligand design, we investigate the impact of heteroarene substituents and thus electronic modified

\footnotetext{
${ }^{a}$ Georg August University Göttingen, Institute of Inorganic Chemistry,

Tammannstraße 4, 37077 Göttingen, Germany.

E-mail: dstalke@chemie.uni-goettingen.de; Web: www.stalke.chemie.uni-goettingen.de; Fax: +49 5513933459

${ }^{b}$ University of Oslo, Centre for Theoretical and Computational Chemistry, Sem Saelandsvei 26, Kjemibygningen, 0371 Oslo, Norway.

E-mail: heike.fliegl@kjemi.uio.no

${ }^{c}$ Georg August University Göttingen, Institute of Physical Chemistry, Tammannstraße 6, 37077 Göttingen, Germany. E-mail: rmata@gwdg.de

$\dagger$ Electronic supplementary information (ESI) available: Details of the multipole refinement, topological and source function analysis, quantum mechanical and delocalization index calculations. CCDC 945366. For ESI and crystallographic data in CIF or other electronic format see DOI: 10.1039/c3cp53756k
}

active ligand periphery on remote metal coordination and aggregation. $^{2}$ The determination of the charge density and the degree of aromaticity in these compounds ${ }^{3}$ is most likely to provide rationales for the observed reactivities since the degree of delocalization influences the metal-ligand charge transfer and hence the complex stability, which can be a decisive feature in catalysis.

The bis(2-benzothiazolyl)phosphane, $\mathbf{1}$, is a most interesting secondary phosphane with the hydrogen atom not bound to the phosphorus atom but to one of the actively coordinating heteroarene rings in a $\mathrm{NH}$-tautomeric way. Therefore it can be regarded as a derivative of $2,\left[\mathrm{Me}_{2} \mathrm{Al}(\mu-\mathrm{Py})_{2} \mathrm{P}\right](\mathrm{Py}=2$-pyridyl $)$ with the organometallic fragment replaced by a proton.

Interestingly, the phosphorus atom in this zwitterionic species still acts as a Lewis base, bridging two $\left\{\mathrm{W}(\mathrm{CO})_{5}\right\}$ moieties (3) as a non-A-frame ligand. In this sense the coordination is reminiscent of the phosphorus(I) zwitterions recently published by Ragogna et $a .^{5}$ We reported in a combined experimental and theoretical charge density study ${ }^{6}$ that the anticipated total conjugation (1a in Scheme 1) is not valid and the phosphanidic $\mu$-coordination mode (1b in Scheme 1) was established both chemically by synthesis of various metal complexes as well as theoretically by topological analysis of a 


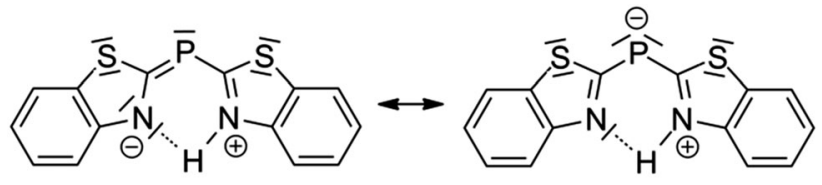

$1 a$

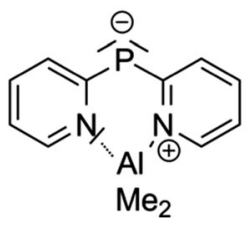

2 1b

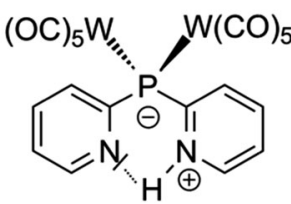

3

Scheme 1 Lewis representation of compounds 1, 2 and 3.

calculated electron density (ED) map. ${ }^{7}$ In accordance with Bader's quantum theory of atoms in molecules (QTAIM), ${ }^{8}$ two valence shell charge concentrations (VSCCs) in the non-bonding region close to the phosphorus atom were interpreted as two lone pairs. Different canonical forms of $\mathbf{1}$ were discussed, specifically considering the nature of the phosphorus-carbon bonds; it was reasoned that they should be classified as single bonds because the two lone pairs and two single bonds added up to a valence shell of the phosphorus atom that obeyed the eight-electron-rule. ${ }^{9}$

To elucidate the topic of aromaticity more deeply, a highresolution single crystal X-ray diffraction dataset was collected at $15 \mathrm{~K}$ and a charge density multipole refinement was accomplished using the XD2006 program suite in the current paper. $^{10}$ The derived charge density distribution $\rho(\mathbf{r})$ was topologically analyzed according to Bader's QTAIM theory. The aromaticity in the heterocyclic and presumably conjugated uncharged molecule $\mathbf{1}$ is now addressed experimentally and theoretically.

The origin of the distinct characteristics of aromatic substances and all their resulting properties can eventually be retraced to the spatial delocalization of electrons associated with cyclic conjugated $\pi$-electron systems. Most undergraduate chemistry students learn molecular orbital (MO) theory and know Hückel's $4 n+2$ rule, but of course they do not consider the approximations made. In his 1931 landmark paper ${ }^{11}$ he laid the foundations of molecular orbital (MO) theory as well as valence bond (VB) theory ${ }^{12}$ and presented solutions for systems like benzene in the framework of his "second approximation" which eventually led to the $4 n+2$ rule.

Approximations are needed for basic models ("unicorns") 13 that are necessary for understanding and predicting observations; no chemical education would be possible and no scientific progress would have been achieved without strong concepts, but they are often mistaken as laws that are set in stone. ${ }^{14}$ The perception of $\mathrm{sp}^{2}$ hybridization is one such concept as well as their strict separation from the atomic $\mathrm{p}$ orbitals that are combined to a number of molecular $\pi$ orbitals that are exclusively used to determine the amount of aromatic stabilization in a substance in the Hückel MO theory framework.

\section{Experimental procedure}

A single crystal of 1 with a size of $0.16 \times 0.17 \times 0.32 \mathrm{~mm}$ was selected from a batch of air-sensitive and volatile crystals that were stored in a glass flask using the X-Temp2 device. ${ }^{15}$ The crystal was mounted on a glass fiber and shock-cooled in the $15 \mathrm{~K}$ gas stream of an Oxford Diffraction HeliJet. Data were acquired using a Bruker APEX2 Ultra system equipped with a Bruker TXS molybdenum rotating anode, Incoatec mirror optics and a Bruker D8 goniometer. Frames were collected at two different detector settings at $2 \theta=-33^{\circ}$ and $-79^{\circ}$ with exposure times of $3.0 \mathrm{~s}$ and $30.0 \mathrm{~s}$, respectively. The data on the collected frames were reduced using SAINT v7.68A. ${ }^{16}$ A numerical absorption correction and data merging was carried out using SADABS 2008/2. ${ }^{17}$ A total of 195525 reflections up to a maximum resolution of $0.44 \AA$ or $\sin (\theta) / \lambda=1.14$ were collected of which 21 severe outliers were rejected, which led to 15005 unique reflections that excluded systematically absent reflections.

\section{Independent atom refinement}

The crystal structure was solved with SHELXS-97 using direct methods. An IAM model was refined using SHELXL- $97^{18}$ by fullmatrix least-squares methods against $F^{2}$. The positions and ADP of non-hydrogen atoms were refined using high order data with a minimum resolution of $0.46 \AA$. The hydrogen atom positions were refined using data with a resolution lower than $1.0 \AA$. The isotropic hydrogen displacement parameters $U_{\text {iso }}$ were constrained to the equivalent isotropic displacement parameters $U_{\text {eq }}$ of the respective bonding partners. The carbon-hydrogen distances were eventually manually set to $1.076 \AA$ and the hydrogen-nitrogen distance was set to $1.032 \AA{ }^{19}$ The resulting model was used to create the starting model for the XD2006 refinement.

\section{XD2006 refinement}

A multipole refinement using the Hansen-Coppens formalism ${ }^{20}$ was carried out in 29 steps. The order $l$ of spherical harmonics was increased to 4 in the course of refinement for non-hydrogen atoms. Only bond-directed dipoles and quadrupoles were refined in the case of the hydrogen atoms. In the initial steps of the refinement, the population parameters of atoms of the same element were constrained to another; mirror symmetry with respect to the ring plane was imposed on the parameters that were refined (with the exception of the sulfur and phosphorus atoms). The chemical constraints were released in the course of the refinement. The bond distances of the hydrogen atoms were reset to neutron diffraction distances in the first steps of the refinement, but were later allowed to relax. Different refinements were evaluated with different values for the radial exponents $n(l)$ for the sulfur and phosphorus atoms. ${ }^{21}$ The best results, indicated by kappa values as close to unity as possible, were obtained by a set of $(4,4,4,4)$ for the sulfur atoms and $(3,4,5,5)$ for the phosphorus atom. The refinement of third- and fourth order Gram-Charlier coefficients was evaluated for the 
phosphorus atom. This led to unphysical effects on the probability density (see ESI $\dagger$ ) and did not improve the model, and was therefore later dropped. ${ }^{22}$ A weighting scheme of $a=0.0125$ and $b=0$ was chosen after careful evaluation of different values using the program DRKplot. $^{23}$ The refinement converged well with a flat and featureless final residual density with a deepest hole and a

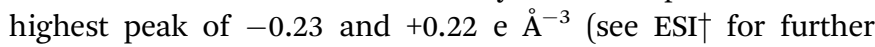
details and plots ${ }^{24}$ of the residual density).

\section{QTAIM analysis}

Properties at selected bond critical points (BCPs) are summarized in Table 1. The obtained molecular graph is shown in Fig. 2. The QTAIM analysis reveals four VSCCs around the phosphorus atom (Fig. 1). The saddle points within these VSCCs correspond to local maxima, $(3,-3)$ critical points, in the negative Laplacian $L(\mathbf{r})$ of the charge density. Bader stated: "the local maxima that are

Table 1 Some results from the QTAIM analysis: electron density $\rho\left(\mathbf{r}_{\mathrm{BCP}}\right)$, Laplacian $L\left(\mathbf{r}_{\mathrm{BCP}}\right)$ and ellipticity $\varepsilon\left(\mathbf{r}_{\mathrm{BCP}}\right)$ at BCPs. Bond path lengths $/(\mathrm{A}-\mathrm{B})$ in bis(benzothiazol2-yl)phosphane (1). A full table including the intermolecular $\mathrm{C}-\mathrm{H} \ldots \mathrm{P}$ and $\mathrm{C}-\mathrm{H} \cdots \mathrm{S}$ contacts can be found in the ESI

\begin{tabular}{lllll}
\hline Bond A-B & $\rho\left(\mathbf{r}_{\mathrm{BCP}}\right)\left[\mathrm{e}^{-3}\right]$ & $L\left(\mathbf{r}_{\mathrm{BCP}}\right)\left[\mathrm{e}^{-5}\right]$ & $\varepsilon\left(\mathbf{r}_{\mathrm{BCP}}\right)$ & $l(\mathrm{~A}-\mathrm{B})[\AA]$ \\
\hline $\mathrm{S}(1)-\mathrm{C}(1)$ & $1.36(2)$ & $-5.61(4)$ & 0.25 & 1.7553 \\
$\mathrm{~S}(1)-\mathrm{C}(2)$ & $1.40(2)$ & $-5.36(5)$ & 0.25 & 1.7408 \\
$\mathrm{~S}(2)-\mathrm{C}(8)$ & $1.32(2)$ & $-3.53(4)$ & 0.21 & 1.7641 \\
$\mathrm{~S}(2)-\mathrm{C}(9)$ & $1.38(2)$ & $-4.53(4)$ & 0.19 & 1.7390 \\
$\mathrm{P}(1)-\mathrm{C}(1)$ & $1.14(3)$ & $-2.27(4)$ & 0.38 & 1.7692 \\
$\mathrm{P}(1)-\mathrm{C}(8)$ & $1.12(2)$ & $-3.00(4)$ & 0.30 & 1.7914 \\
$\mathrm{~N}(1)-\mathrm{C}(1)$ & $2.46(2)$ & $-30.17(7)$ & 0.04 & 1.3405 \\
$\mathrm{~N}(1)-\mathrm{C}(7)$ & $2.17(2)$ & $-20.5(1)$ & 0.10 & 1.3826 \\
$\mathrm{~N}(2)-\mathrm{C}(8)$ & $2.50(2)$ & $-31.28(8)$ & 0.12 & 1.3229 \\
$\mathrm{~N}(2)-\mathrm{C}(14)$ & $2.23(2)$ & $-21.6(1)$ & 0.06 & 1.3825 \\
$\mathrm{C}(2)-\mathrm{C}(7)$ & $2.16(2)$ & $-20.00(7)$ & 0.14 & 1.4024 \\
$\mathrm{C}(9)-\mathrm{C}(14)$ & $2.17(2)$ & $-19.68(7)$ & 0.20 & 1.4060
\end{tabular}
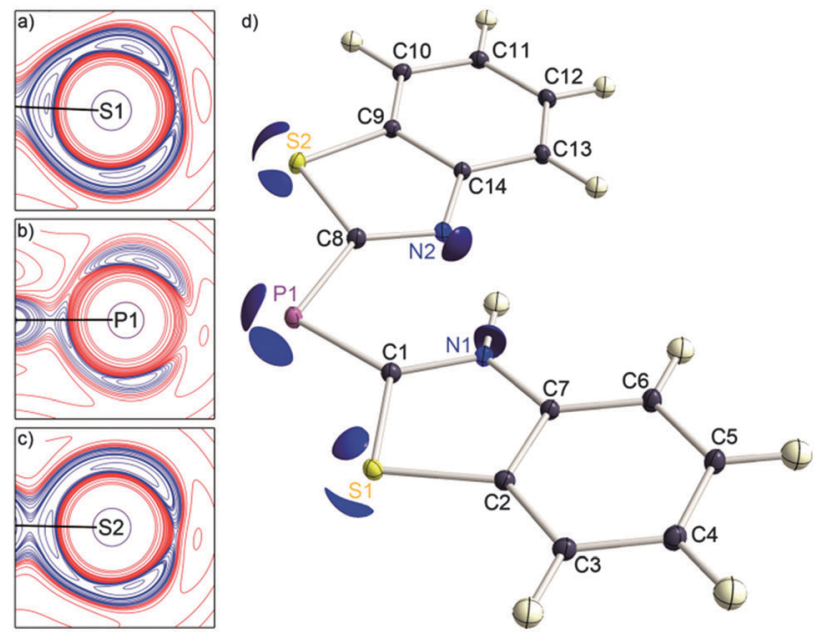

Fig. 1 (a)-(c) 2D Laplacian maps through nonbonding $(3,-3)$ critical points and phosphorus and sulfur atoms, respectively; red/blue lines determine positivenegative isovalues, respectively. (d) 3D molecular structure (anisotropic displacement parameters at the $50 \%$ probability level) of 1 including Laplacian isosurfaces visualizing the regions of charge concentrations (isosurface values: -3.3 e $\AA^{-5}$ for phosphorus, -8.5 e $\AA^{-5}$ for sulfur, -45 e $\AA^{-5}$ for nitrogen atoms). 3D graphics were created with MoleCoolQt. ${ }^{4}$

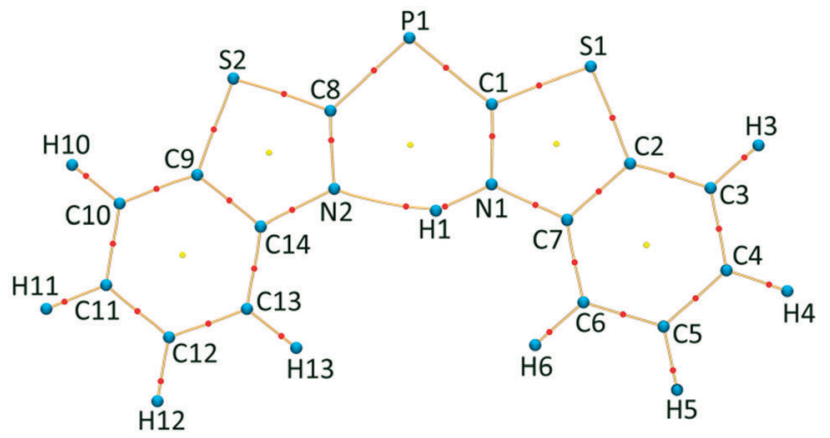

Fig. 2 Molecular graph of 1 with a numbering scheme. Graphics were created using POV-Ray. ${ }^{27}$

created within the VSCC of a bonded atom provide a mapping of the bonding and nonbonding electron pairs." 25 It is important to note that Bader refers to spatially localized electron pairs in the sense of the valence shell electron pair repulsion (VSEPR) model. ${ }^{26}$ Two VSCCs located on the P-C-bonds are expected and observed while the other two phosphorus VSCCs are not involved in chemical bonding, rendering them potential lone pair indicators. In an analogous manner to 2 , the presence of two nonbonding lone pairs at the phosphorus atom confirms the theoretically predicted and chemically indicated phosphanidic character of $\mathbf{1}$.

If the electrons in $\mathbf{1}$ strictly obey the simplistic models mentioned in the introduction then one Lewis lone pair of each sulfur atom would be assigned to a p-orbital as part of the delocalized system. The other lone pair would be localized in an $\mathrm{sp}^{2}$ type orbital. This is a consequence of the approximation of strict $\sigma / \pi$ separation ("electrons of the first and the second kind” in Hückel's paper), which is of course not entirely valid, especially for heterocyclic systems containing third row elements.

The structure of $\mathbf{1}$ almost perfectly obeys another established prerequisite for aromaticity, namely planarity. This is also manifested in the Laplacian distribution, as three VSCCs in a quasi-trigonal distribution are present around the second row elements. This would be in accordance with the concept of $\mathrm{sp}^{2}$ hybridization. In contrast, four VSCCs are found around the sulfur atoms in a similar distribution compared to those VSCCs at the phosphorus atom. None of the lone pair-related sulfur VSCCs is located in the ring plane, different to those around the nitrogen atoms.

However, an interpretation of the observed VSCCs as a full pair of localized two-electron basins as in the early statement of Bader et al. would directly contradict the assumption of aromaticity because it implies the lack of an aromatic electron sextet in the ring. Now we reached a point in our critical analysis where it becomes obvious that the simple valence bond model of localized electron pairs stalls: there has never been a doubt in the chemical community that sulfur-containing heterocycles such as thiophene, thiazole, and benzothiazole have to be considered aromatic. ${ }^{28}$ It is also unlikely that the aromaticity of the benzothiazole moieties should vanish e.g. by the mere existence of the bridging phosphorus atom in $\mathbf{1}$. 
Table 2 Atomic integrated charges and Lagrangian values from the experimentally and theoretically derived charge density maps. The DF-LMP2/cc-pVTZ optimized density of 1 was used for theoretical results

\begin{tabular}{llrllr}
\hline & Experimental & & & Theoretical & \\
\cline { 2 - 3 } Atom & $Q$ (Atom) $[\mathrm{e}]$ & $L($ Atom $)[\mathrm{au}]$ & & $Q$ (Atom) $[\mathrm{e}]$ & $L($ Atom $)[\mathrm{au}]$ \\
\hline $\mathrm{S}(1)$ & +0.203 & $1.73 \times 10^{-3}$ & +0.235 & $1.26 \times 10^{-6}$ \\
$\mathrm{~S}(2)$ & +0.070 & $5.61 \times 10^{-4}$ & +0.205 & $-4.57 \times 10^{-5}$ \\
$\mathrm{P}(1)$ & +0.636 & $4.98 \times 10^{-5}$ & +1.137 & $-6.34 \times 10^{-5}$ \\
$\mathrm{~N}(1)$ & -1.133 & $5.17 \times 10^{-4}$ & -1.293 & $1.22 \times 10^{-4}$ \\
$\mathrm{~N}(2)$ & -1.210 & $-2.84 \times 10^{-4}$ & -1.168 & $8.23 \times 10^{-5}$ \\
$\mathrm{C}(1)$ & -0.057 & $-3.64 \times 10^{-3}$ & -0.272 & $-4.49 \times 10^{-4}$ \\
$\mathrm{C}(2)$ & -0.157 & $-3.57 \times 10^{-4}$ & -0.192 & $3.99 \times 10^{-5}$ \\
$\mathrm{C}(3)$ & -0.092 & $1.21 \times 10^{-3}$ & +0.011 & $5.44 \times 10^{-7}$ \\
$\mathrm{C}(4)$ & -0.148 & $8.44 \times 10^{-4}$ & -0.020 & $2.37 \times 10^{-5}$ \\
$\mathrm{C}(5)$ & -0.160 & $2.30 \times 10^{-4}$ & -0.016 & $-2.43 \times 10^{-5}$ \\
$\mathrm{C}(6)$ & -0.136 & $7.87 \times 10^{-4}$ & -0.007 & $-4.59 \times 10^{-5}$ \\
$\mathrm{C}(7)$ & +0.314 & $-1.35 \times 10^{-3}$ & +0.430 & $5.92 \times 10^{-6}$ \\
$\mathrm{C}(8)$ & +0.046 & $1.86 \times 10^{-3}$ & -0.148 & $1.41 \times 10^{-4}$ \\
$\mathrm{C}(9)$ & -0.148 & $2.25 \times 10^{-3}$ & -0.219 & $5.83 \times 10^{-5}$ \\
$\mathrm{C}(10)$ & -0.080 & $-1.64 \times 10^{-3}$ & +0.007 & $-1.85 \times 10^{-4}$ \\
$\mathrm{C}(11)$ & -0.171 & $6.83 \times 10^{-4}$ & & -0.027 & $-6.11 \times 10^{-6}$ \\
$\mathrm{C}(12)$ & -0.133 & $6.63 \times 10^{-5}$ & -0.023 & $-1.52 \times 10^{-4}$ \\
$\mathrm{C}(13)$ & -0.098 & $-2.05 \times 10^{-3}$ & -0.022 & $-3.28 \times 10^{-5}$ \\
$\mathrm{C}(14)$ & +0.283 & $1.81 \times 10^{-3}$ & +0.434 & $-3.12 \times 10^{-4}$ \\
\hline
\end{tabular}

Non-bonding VSCCs should not be mistakenly interpreted as evidence for the existence of $\mathrm{sp}^{3}$ type "rabbit ear" lone pairs. It might be tempting to draw this conclusion in the case of 2 because the individual VSCC distributions around the phosphorus and sulfur atoms are so close to tetrahedral symmetry. However, integration of the atomic basin clearly indicates electronic depletion of the phosphorus atom in $\mathbf{1}(+0.64$ exp. and +1.1 theory, Table 2 ) and in 2 ( +0.56 exp.) indicating that the small amount of lone pair density is structured in a tetrahedral fashion but would not stand for full four electrons. The same is valid for the ring sulfur atoms in $\mathbf{1}(+0.20$ and +0.07 exp. and +0.24 and +0.21 theory, Table 2). It is worthy to note in this context that this structured density is attractive to the partially positively charged hydrogen atoms at the aromatic $\mathrm{C}_{6}$ perimeter and we identified weak intermolecular hydrogen bonds involving $\mathrm{C}-\mathrm{H} \cdots \mathrm{P}$ and $\mathrm{C}-\mathrm{H} \cdots \mathrm{S}$ from a molecular graph of the crystal packing (Fig. 3). The values at the BCPs are well within those reported for similar $\mathrm{C}-\mathrm{H} \cdots \mathrm{S}$ contacts. ${ }^{29}$ We employed a recently developed method to quantify and visualize those non-covalent interactions. ${ }^{30} \mathrm{~A}$ reduced density gradient (RDG) grid around a molecule of $\mathbf{1}$ was calculated from the experimentally determined electron density, taking into account neighboring molecules in the crystal packing. The sign of the second eigenvalue of the Hessian matrix of $\rho(\mathbf{r})$ in a point $\mathbf{r}$ enables us to distinguish whether an interaction is bonding or nonbonding. ${ }^{28 a}$ The property $\rho(\mathbf{r}) \cdot \operatorname{sign}\left[\lambda_{2}(\mathbf{r})\right]$ was then projected on an isosurface of the RDG. A preliminary version of the program NCImilano ${ }^{31}$ was kindly provided by G. Saleh and used for the calculations. In those regions where $\lambda_{2}$ is negative, an attractive (bonding) interaction is present. The $\mathrm{C}-\mathrm{H} \cdots \mathrm{S}$ and $\mathrm{C}-\mathrm{H} \cdots \mathrm{P}$ contacts that are visible in the molecular graph in Fig. 3 are reproduced in the NCI plot (Fig. 4); in addition, weak intermolecular S2 $\cdots \mathrm{S} 2$ and $\mathrm{P} 1 \cdots \mathrm{S} 2$ contacts are present in the NCI plot. No chalcogen-chalcogen or pnictogen-chalcogen

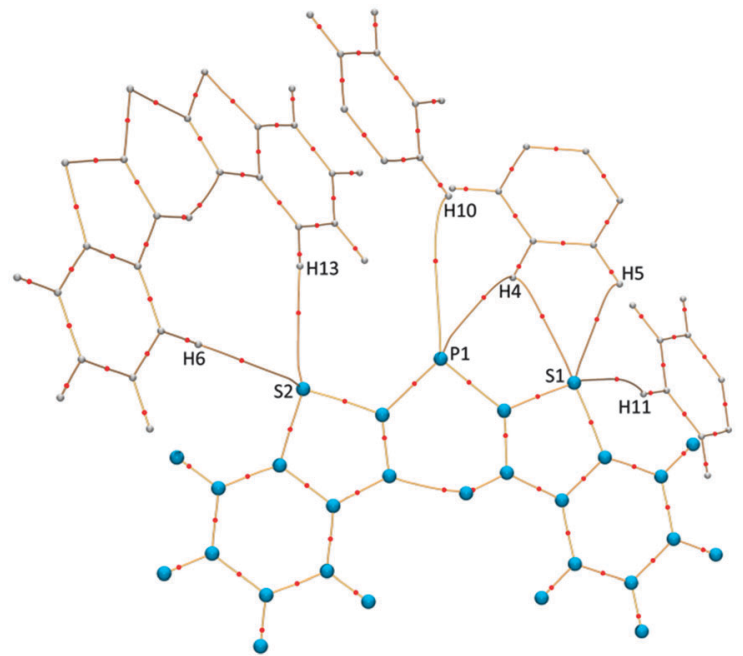

Fig. 3 Molecular graph with $\mathrm{C}-\mathrm{H} \ldots \mathrm{S}$ and $\mathrm{C}-\mathrm{H} \ldots \mathrm{P}$ hydrogen bond paths to crystallographically next lattice neighbors (blue spheres: atomic positions; red spheres: BCPs; gray spheres: symmetry-generated atoms). Please refer to the ESIt for properties at the intermolecular BCPs. Graphics were created using POV-Ray. ${ }^{27}$

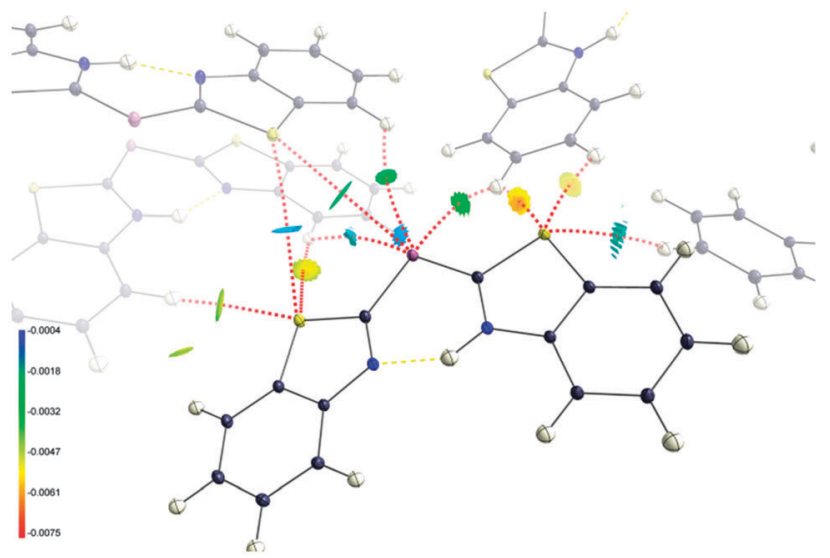

Fig. 4 Visualization of non-covalent interactions in the crystal structure of 1. Only attractive interactions were plotted. A range of values -0.015 a.u. $<\rho(\mathbf{r})$. $\operatorname{sign}\left[\lambda_{2}(\mathbf{r})\right]<0$ was projected onto an RDG isosurface of 0.5 a.u. Graphics were created using MoleCoolQt. ${ }^{4}$

bonds should be deduced from the plot, however. These interactions are very weak judging from the low value of $\rho(\mathbf{r})$ at the corresponding RDG isosurfaces.

Bent's rule stating that the $\mathrm{p}$ character of bonding orbitals is maximized in bonds towards more electronegative substituents actually serves well to predict the present bonding situation around the sulfur and phosphorus atoms because the bond angle is determined by the $\mathrm{s}$ or $\mathrm{p}$ character of the bonding orbitals. ${ }^{32}$ The percentage s-character of the bonds can be estimated to be nearly zero, given the angles around S1 and S2 of $91.20^{\circ}$ and $90.40^{\circ}$, respectively. This rather coarse estimation indicates that the chemical bonds towards the neighboring carbon atoms are dominated by two of the sulfur p orbitals; hence, the two lone pairs consist of equal $\mathrm{p}$ and $\mathrm{s}$ contributions. The phosphorus atom with its bond angle of $98.60^{\circ}$ will 
presumably have a slightly higher s character in its bonds towards the carbon atoms. The lower absolute values of $\rho(\mathbf{r})$ and $L(\mathbf{r})$ at the $\mathrm{P}-\mathrm{C}$ bond critical points compared to those of the $\mathrm{S}-\mathrm{C}$ bond critical points display the more diffuse character that goes along with higher s character of a bond.

The presence of the VSCCs around the sulfur and phosphorus atoms renders it even more challenging to determine the degree of electron delocalization in $\mathbf{1}$. The delocalization of electrons is a prerequisite for the aromatic behavior of a substance although the degree of delocalization would not need to be a quantitative measure of aromaticity. One of the main characteristics of aromaticity seems to be its ambiguity because it occurs in many gradations. Heteroaromatic and annulated systems show a different degree of aromaticity compared to the aromatic archetype benzene. The exact quantity is hard to determine unambiguously although many different approaches to this problem have been proposed. ${ }^{33}$ They are based on experimental observables such as thermochemical, structural, $^{34}$ magnetic ${ }^{35}$ and spectroscopic properties ${ }^{36}$ as well as on quantum-chemical calculations. ${ }^{1 d, 37}$

\section{The ellipticity as a descriptor for electron delocalization}

The electron density is one of the very fundamental experimental observables, and properties with a direct relation to the ED can as well be considered an experimental observable. There have been early approaches to extract information about the degree of electron delocalization directly from the topology of an ED map following QTAIM. One of the earliest is still employed and was published by Bader et $a l^{38}$ and Cremer et al. ${ }^{39}$ Bonding characteristics were derived from properties such as the values of $-\nabla^{2} \rho(\mathbf{r})$ and $\rho(\mathbf{r})$ at bond critical points (BCPs), and the existence of bond ellipticity $\varepsilon$ is one central criterion for conjugation in these studies. The ellipticity $\varepsilon=\left[\left(\lambda_{1} / \lambda_{2}\right)-1\right]$ is the ratio of those eigenvalues $\lambda_{1}$ and $\lambda_{2}$ of the Hessian matrix that correspond to directions perpendicular to the bond path. Its value provides a measure of the deviation of the bonding density from cylindrical symmetry with $\varepsilon=0$ for cylindrical symmetry and $\varepsilon>0$ e.g. for bonds with $\pi$ character. Ellipticities increase from 0.0 to 0.23 and 0.45 from ethane to benzene and ethylene. ${ }^{37 b}$ Evaluating $\varepsilon$ along bond paths and not only at BCPs has been proven to be advantageous, especially for the case of polar bonds ${ }^{40}$ and N-heterocyclic carbenes. ${ }^{41}$

The ellipticity has to be evaluated carefully; only the eigenvalue $\lambda_{3}$ corresponding to the vector pointing towards the direction of largest positive curvature can be considered to be statically directed parallel to the bond path, while the two remaining eigenvectors that are used for the construction of $\varepsilon$ may in principle point towards any direction perpendicular to the first. For this reason, it is of great importance to know the angles of these vectors when evaluating ellipticity profiles, e.g. relative to the normal vector of the molecular plane, as has recently been shown by Farrugia and Khalaji. $^{42}$ If $\lambda_{2}$, the eigenvalue corresponding to the smallest negative curvature, is taken into account, the angle has to be
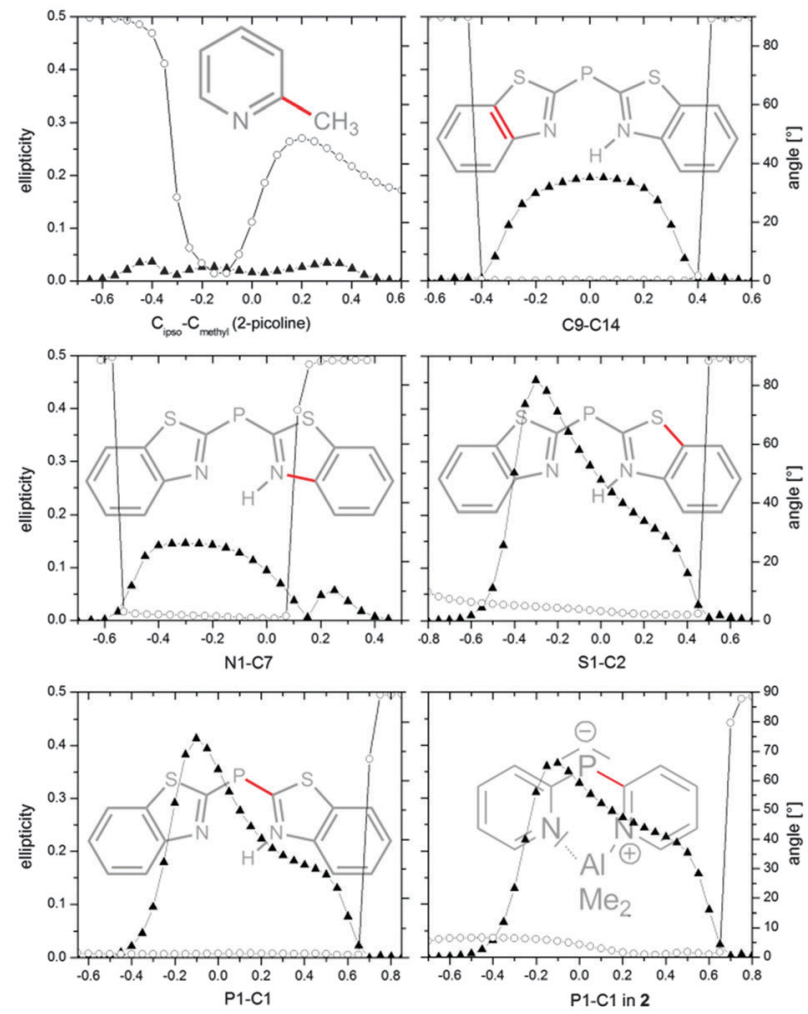

Fig. 5 Ellipticity $(\boldsymbol{\Delta})$ and $\varphi(\bigcirc)$ bond profiles. Only representative profiles are shown. Full data can be found in the ESI; + the exocyclic $\mathrm{C}-\mathrm{C}$ single bond in 2-picoline was taken as the benchmark and calculated from the data used in an earlier publication. ${ }^{40 a}$

close to zero for bonds with significant $\pi$ contribution. Only then the ellipticity is caused by expansion of the charge density perpendicular to the ring plane.

The C9-C14 bond (Fig. 5, top right) in 1 is taken as an internal standard for a homoatomic nearly unpolarized aromatic bond. The exocyclic bond in 2-picoline, which has been studied by us earlier, ${ }^{40 c}$ serves as an external standard single bond (Fig. 5, top left). The $\varepsilon$ profile as well as the angular orientation of $\lambda_{2}$ along the C9-C14 bond is indeed typical for aromatic bonds showing an overall symmetry with $\varepsilon>0$ and $\varphi$ angles close to zero in the regions of pronounced ellipticity. In contrast, the profile shown in Fig. 5 (top right) has the expected shape of a single bond with an ellipticity close to zero and a rather unspecific distribution of the angle $\varphi .{ }^{8}$ The profiles for bonds involving heteroatoms show even larger maximum $\varepsilon$ values, and $\varphi$ adopts values close to zero in the regions of high ellipticity. It is important to note that this behavior is equally observed for the central phosphorus-carbon bonds (Fig. 5, bottom left and right).

The relatively uniform high maximum values of $\varepsilon$ should not be erroneously interpreted to indicate strong charge accumulation: the absolute values of $\lambda_{1}, \lambda_{2}, \lambda_{3}$, and $L(\mathbf{r})$ in the regions of high ellipticity cover a wide range, and it is only the ratio of $\lambda_{1}$ and $\lambda_{2}$ which defines $\varepsilon$. The regions of high ellipticity in the phosphorus-carbon bonds have the lowest values of $L(\mathbf{r})$ among all bonds in 1 (see Table 1 and ESI $\dagger$ ). The tendency in the values of $L(\mathbf{r})$ for the nonbonding VSCCs is congruent with that for the 
bonding VSCCs, exhibiting the highest values for nitrogencarbon bonds and carbon-carbon bonds.

Despite the apparent differences in the various profile shapes of each particular bond, it has to be concluded that they share the distinct characteristics of pronounced ellipticity accompanied by the principal vector $\lambda_{2}$ arranged perpendicular to the molecular plane. In other words: according to the results from established QTAIM methods, all bonds between nonhydrogen atoms in $\mathbf{1}$ show a significant $\pi$ character.

\section{Source function calculations}

In order to gain a second, independent measure on aromaticity, we employed the source function (SF) to determine the degree of electron delocalization. Bader and $\mathrm{Gatti}^{43}$ have shown that the ED at a reference point $\mathbf{r}$ can be taken as a sum of contributions from a local source $\operatorname{LS}\left(\mathbf{r}, \mathbf{r}^{\prime}\right)$ operating at all other points $\mathbf{r}^{\prime}$. The SF is essentially a Green's function indicating to which extent a cause - here: the Laplacian of the density at the point $\mathbf{r}^{\prime}$ - induces an effect, the ED at the reference point $\mathbf{r}$. An integration of the SF over an atomic basin yields the atomic contribution to the ED at a reference point.

It can be concluded that the SF may in principle be used to determine the degree of electron delocalization in any electronic system. Gatti et al. have recently demonstrated the potential of the SF for the evaluation of electron delocalization ${ }^{44}$ and introduced a new SF-based local aromaticity descriptor in a proof-of-principle study. ${ }^{45}$ This descriptor requires benchmark values from unsaturated systems and is only intended to be used with homoaromatic systems.

Another approach was suggested in the same publications, which we applied in this paper. Reference points should be used that reside on a line passing through the BCP approximately perpendicularly to the plane of the aromatic ring; this approach was successfully utilized with theoretical and experimental data of benzene and other compounds. ${ }^{44,45}$ Electron delocalization is believed to take place predominantly in the conjugated $\pi$ system, and BCPs are located close to the nodal planes of $\pi$ orbitals in the $\sigma$ electron density region dominating the ring plane. ${ }^{46}$ However, for conjugated systems, SF contributions from remote atomic basins should increase with increasing $\pi$ character of the electron density at the reference point. In this study reference points were chosen at different distances between $0 a_{0}$ and $2.0 a_{0}$ to the ring plane. This corresponds to a maximum distance of $1.06 \AA$ A. Only the results for $0 a_{0}$ and $2.0 a_{0}$ will be shown here.

Relative contributions from every atomic basin to the total ED at all given reference points were calculated. Not surprisingly, contributions from neighboring atoms to reference points in the ring planes are dominant. Contributions from neighboring atoms decrease significantly with increasing distance of the reference point from the plane (see Fig. 6 and 7 for comparison and the ESI $\dagger$ for further details). The opposite tendency is observed for relative contributions from second next neighboring atoms. The corresponding values increase constantly and significantly the further away a given reference point is located from the ring plane. This can be taken as an indication for $\pi$ delocalization.
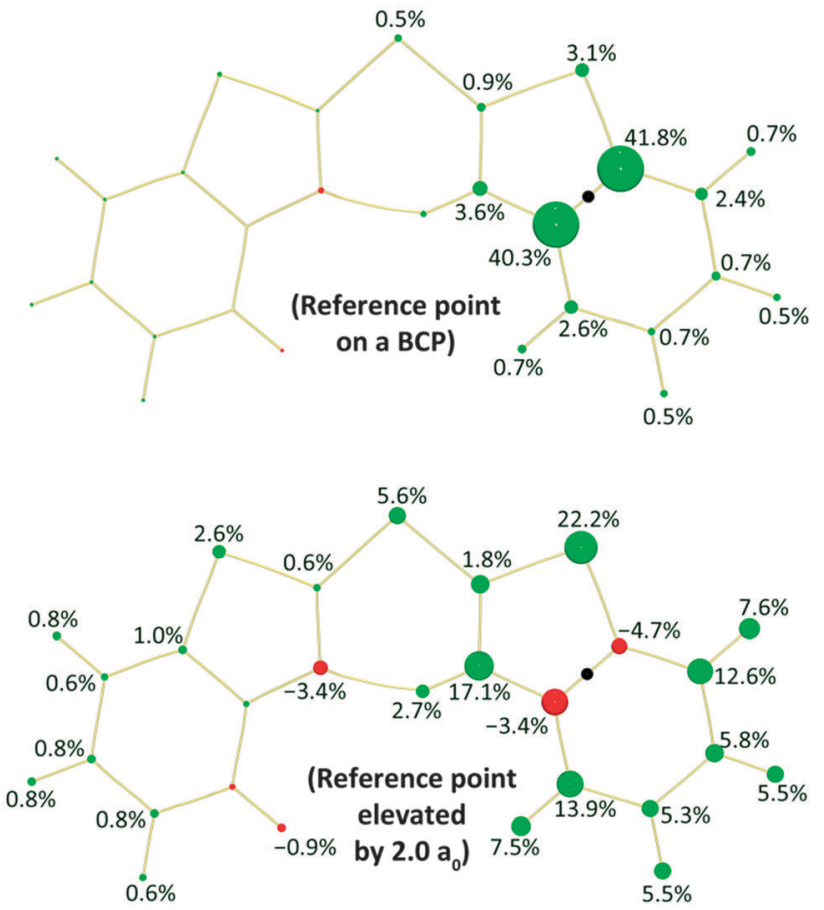

Fig. 6 Graphical representation of the atomic SF contributions in the molecular graph. The reference point on the $\mathrm{C} 2-\mathrm{C} 7$ bond is indicated by a black dot. Percentage SF contributions except those with absolute values below $0.5 \%$ are given next to each atom. The reference point is on a BCP in the first row and elevated by $2.0 a_{0}$ from its initial position in the second row. The sphere radii are scaled proportional to the respective percentage contribution. Graphics were created using POV-Ray. ${ }^{27}$
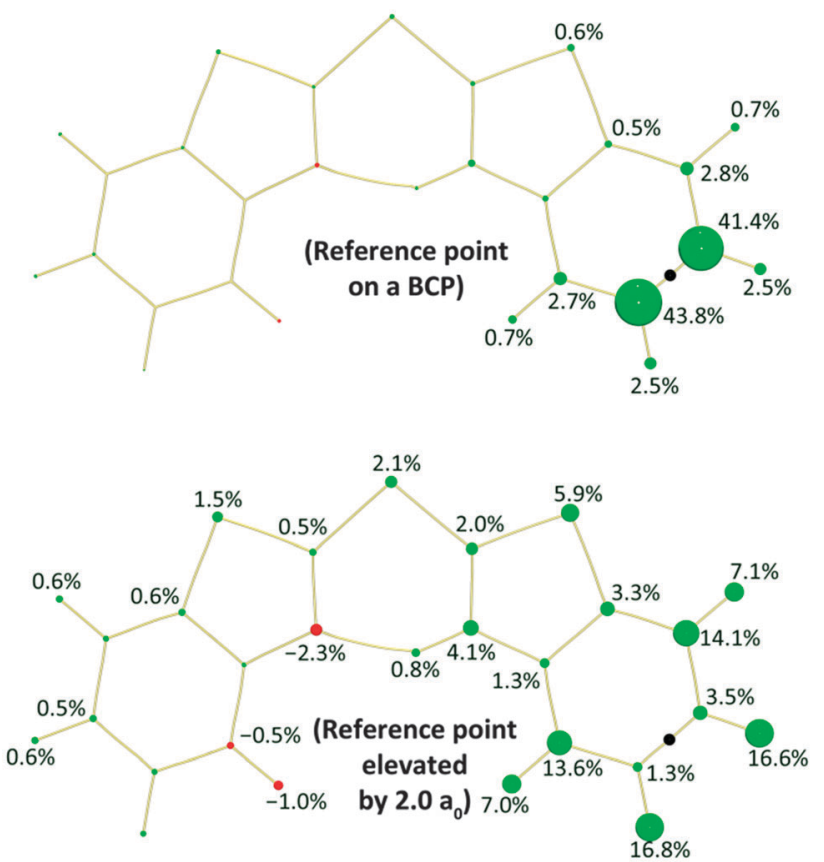

Fig. 7 Graphical representation of the atomic SF contributions in the molecular graph. The reference point is on the C4-C5 bond. It is on a BCP in the first row and elevated by $2.0 a_{0}$ from its initial position in the second row. The sphere radii are scaled proportional to the respective percentage contribution. Graphics were created using POV-Ray. ${ }^{27}$ 
The same tendency is true for relative contributions from atoms further away, but on a somewhat smaller overall scale. The general trend applies to contributions from all non-hydrogen atoms in the molecule with the heteroatom contributions stronger than carbon atoms (see ESI $\dagger$ ). While the general tendency seems to indicate delocalization, we can only speculate on the amount of electron delocalization because there is no reference data from comparable heterocyclic aromatics we could possibly refer to.

\section{Theoretical calculations}

Certainly the best approach when discussing aromaticity is to combine many complementary methods, ${ }^{28 b}$ particularly in such borderline cases. Having this in mind, we carried out theoretical calculations on compound $\mathbf{1}$ in addition to SF calculations and topological analysis. All wave function calculations were carried out using the Molpro 2010.1 program package. ${ }^{47}$ The structure was first optimized at the DF-LMP2/ cc-pVTZ ${ }^{48}$ level of theory, its thermodynamic stability being confirmed relative to the $\mathrm{P}-\mathrm{H}$ tautomer. ${ }^{7}$ The nucleus independent chemical shift (NICS) has become a general tool for the determination of aromaticity based on the magnetic criteria, ${ }^{37}$ although its universal reliability has not remained unquestioned. ${ }^{49}$ Nevertheless, the NICS(0) values for the five-membered rings in 1 were calculated to be -6.53 and $-7.85 \mathrm{ppm}$ for the protonated and the nonprotonated ring, respectively. The benzothiazole molecule 4 , at the same level of theory (GIAO-DF-HF/cc-pVTZ), ${ }^{50}$ has a value of $-9.86 \mathrm{ppm}$. This would indicate aromaticity, even if at a somewhat smaller scale than the unsubstituted parent compound.

In a second set of calculations, we applied alternative measurements for aromaticity. Magnetically induced current densities were calculated using GIMIC. ${ }^{51}$ The latter is an independent program interfaced to Turbomole. ${ }^{52}$ It uses the magnetically perturbed density matrices from nuclear magnetic shielding calculations, the one-electron density matrix as well as basis-set information as input data. The magnetically induced current densities are obtained using gauge including atomic orbitals (GIAOs) also known as London orbitals. ${ }^{53}$ Their employment leads to a faster basis set convergence. Thus, accurate gauge-independent current densities can already be obtained using split-valence SVP quality basis sets. The necessary nuclear magnetic shielding values were calculated using the B3LYP functional, ${ }^{54}$ as implemented in Turbomole version $6.3^{52}$ together with a triple-zeta quality basis set (def2-TZVPP) augmented with polarization functions. ${ }^{55}$

The shielding values in $\mathbf{1}$ as well as those for the reference substance benzene are given in the ESI $\dagger$ (at both HF and DFT levels of theory). They confirm the aromatic character of the sixmembered rings. The calculated shieldings of the carbon atoms in the five-membered rings indicate reduced or even cancelled aromaticity (see the ESI $\dagger$ for details).

\section{Induced ring currents}

The susceptibility of the ring current (in $\mathrm{nA} \mathrm{T}^{-1}$ ), which is denoted in the following as ring-current strength, provides reliable information regarding the degree of molecular aromaticity according to the ring current criterion as well as detailed information about the current pathways in complex molecular ring systems. ${ }^{56}$ The current strengths and current pathways are obtained by numerical integration of the current density passing through cut planes perpendicularly to selected bonds of the studied molecules. The sign and magnitude of the ring currents indicate whether molecular rings are aromatic, antiaromatic, or nonaromatic thus having diatropic, paratropic, or vanishing net ring currents. ${ }^{57}$ Diatropic ring currents are defined to generate a magnetic field opposing the external field, whereas paratropic currents circulate in the opposite (non-classical) direction strengthening the external magnetic field. ${ }^{36 c, 58}$ For example the ring-current strength for benzene is $11.8 \mathrm{nA} \mathrm{T}^{-1}$ and can be used as a reference value for aromatic molecules. An overview of the GIMIC method and related applications can be found in ref. $1 b$. The current pathway pictures are obtained from GIMP and Jmol. ${ }^{59}$ Mayavi2 has been used for the visualization of the current vectors. ${ }^{60}$

In Fig. 8, the calculated magnetically induced current density as well as a schematic overview of the current pathways and integrated current strengths is displayed. For all rings the dominating currents are found to be diatropic. Thus, according to the magnetic criterion, all rings can be considered as aromatic. The respective current pathways obtained through explicit integration of the current density for selected bonds are marked in red. Calculated current strength values are given in black. The strongest currents of 11.4 and $17.2 \mathrm{nA} \mathrm{T}^{-1}$ flow around the six membered rings, while the currents circling around the five membered rings have values of 4.7 and $7.3 \mathrm{nA} \mathrm{T}^{-1}$ which are about $60 \%$ weaker. Thus, both five membered rings can be regarded as approximately half as aromatic as benzene. The smaller current strengths of 6.3 and $1.9 \mathrm{nA} \mathrm{T}^{-1}$ obtained for the $\mathrm{C}-\mathrm{C}$ bonds fusing the five and six membered rings can be understood, since at these bonds the two current contributions flow in opposite direction and therefore partly cancel each other.

Only very weak currents between 0.6 and $1.0 \mathrm{nA} \mathrm{T}^{-1}$ are transported along the $\mathrm{C}-\mathrm{P}-\mathrm{C}$ and $\mathrm{N}-\mathrm{H}-\mathrm{N}$ bridges (marked green), showing that this molecule contains two nearly independent current circuits around the five and six membered rings at each side of the bridging phosphorus atom.

\section{Delocalization indices}

The DF-LMP2/cc-pVTZ density of $\mathbf{1}$ was also used to compute the delocalization indices ${ }^{61}$ between all atoms with the AIMAll program suite. ${ }^{62}$

The delocalization index $\delta(\mathrm{A}, \mathrm{B})$ is obtained from the double integration of the exchange-correlation density over the atomic basins of atoms A and B; it essentially serves as a measure of how many electrons are shared or exchanged between a pair of atoms A and B. It should not be mistakenly be interpreted in terms of bond order. The bond order can only be derived from the delocalization index in the special case of non-polar bonds with equally shared bonding electrons. In such a situation, a value of $\delta(\mathrm{A}, \mathrm{B})=1$ would be expected for a single bond. The value would significantly decrease in polar bonds because more charge density is concentrated in one atomic basin than in the other and thus not shared between the atoms. 

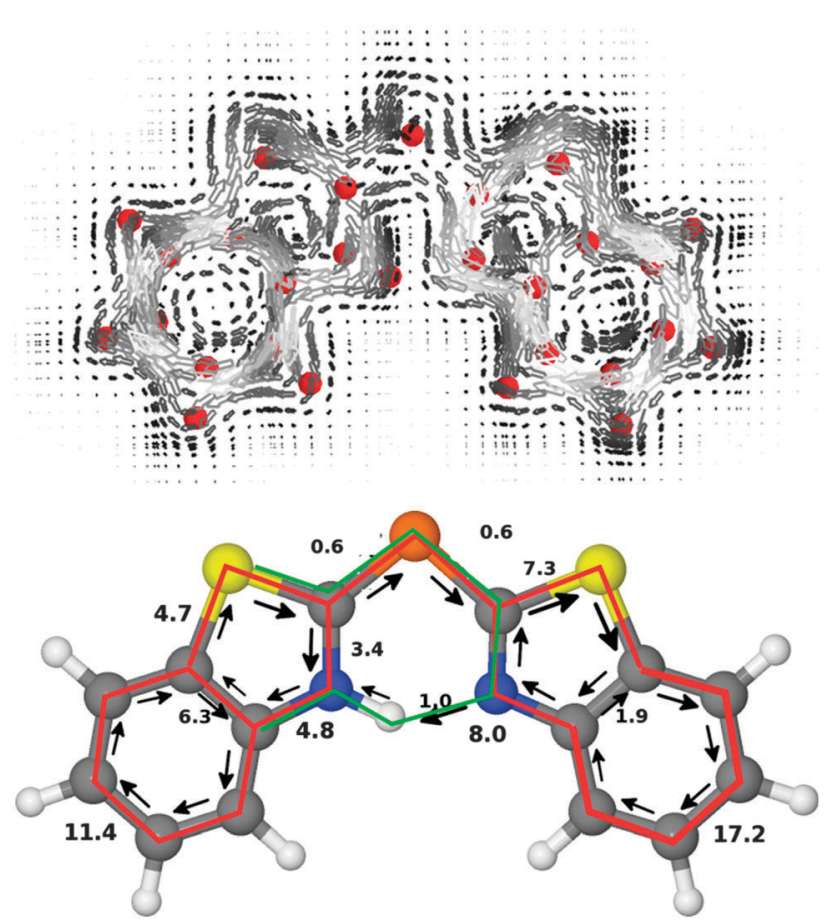

Fig. 8 Top: the magnetically induced current density for $\mathbf{1}$ calculated at the DFT B3LYP/TZVPP level. The current is displayed in a plane parallel to the molecular plane and 1 Bohr above it. Diatropic currents are assumed to circle clockwise and paratropic ones counter clockwise. The positions of the nuclei are marked red. Bottom: the schematic picture of the calculated current pathways in 1. The numbers in black denote explicitly integrated current strengths for selected bonds. The dominating diatropic current pathway is colored red. A very small current of $0.6-1.0 \mathrm{nA} \mathrm{T}^{-1}$ (marked green) is transported along the C-P-C bridge and across the hydrogen bridge.

The delocalization index is based on quantum-mechanical calculations. The results strongly vary with the used level of theory while the dependence on the size of the used basis set is less pronounced. ${ }^{61}$ If comparisons between different molecules are to be made, it is important to have in mind that numerical values should only be compared between results obtained from the same level of theory. In order to be able to compare 1 to some benchmark systems, we calculated molecular densities from geometry-optimized structures of benzothiazole (4) and phosphorine (5) at the same level of theory and basis set as for $\mathbf{1}$ and used the corresponding $\delta(\mathrm{A}, \mathrm{B})$ for comparison.

For carbocyclic aromatic systems like benzene, the delocalization index of adjacent carbon atoms is generally larger than unity, reflecting a bond order higher than 1 . It was found that the $\delta(\mathrm{A}, \mathrm{B})$ values of para-related carbon atoms are larger than those of metarelated atoms, and an index called para-delocalization index (PDI) defined as the mean of all $\delta(\mathrm{A}, \mathrm{B})$ values between para-related atoms in a ring has been proposed. ${ }^{61 a}$

As there are no para-related atoms in five-membered rings, the PDI cannot be used for the thiazole moiety. For heteroaromatic rings containing only one heteroatom, the difference between the $\delta(\mathrm{A}, \mathrm{B})$ values for the respective pairs of atoms belonging to formal double and formal $\mathrm{C}-\mathrm{C}$ single bonds was proposed as a comprehensive index (the smaller the difference, the more distinct the aromatic character) ${ }^{61 a}$ but this approach

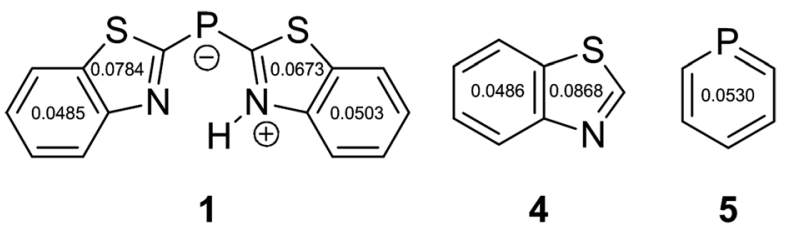

Fig. 9 Delocalization index $\delta(\mathrm{A}, \mathrm{B})$ results: the numbers in six-membered rings are PDI values obtained according to ref. $61 \mathrm{~b}$ and the numbers in five-membered rings are the mean values for those $\delta(\mathrm{A}, \mathrm{B})$ of 1,3-related atoms.

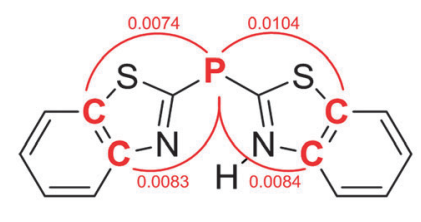

1

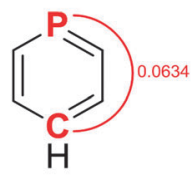

4
Fig. 10 Values of $\delta(A, B)$ for selected 1,4-related atoms in 1 and 4 are given in red.

is for obvious reasons not valid for thiazole rings, too. We chose to take the mean value of the $\delta(\mathrm{A}, \mathrm{B})$ of 1,3-related atoms in the heterocycles of $\mathbf{1}$ and $\mathbf{4}$ instead, as proposed by others as well. ${ }^{63}$ The results are displayed in Fig. 9.

These PDI values qualitatively agree between 1 and 4 . The mean value of $\delta(\mathrm{A}, \mathrm{B})$ for 1,3-related atoms in the five-membered rings of $\mathbf{1}$ is significantly lower than in $\mathbf{4}$, which is even more pronounced in the protonated thiazole ring of $\mathbf{1}$. This can be interpreted as a lowered degree of electron delocalization compared to the non-protonated, non-substituted parent compound 4. No corresponding value for the PDI value of phosphorine 5 can be calculated for compound $\mathbf{1}$. Hence, the $\delta(\mathrm{P}, \mathrm{C})$ for the phosphorus atom and the para-carbon atom and the respective 1,4-related $\delta(\mathrm{P}, \mathrm{C})$ in $\mathbf{1}$ are given in Fig. 10. The corresponding $\delta(\mathrm{P}, \mathrm{C})$ are almost a magnitude smaller in $\mathbf{1}$ compared to $\mathbf{5}$. More details can be found in the ESI. $\dagger$

\section{Conclusions}

All employed methods indicate electron delocalization including all non-hydrogen atoms in $\mathbf{1}$. It is safe to state that sulfur as well as phosphorus atoms contribute to the delocalized charge density. However, our results concerning the $\mathrm{P}-\mathrm{C}$ bonds are somewhat ambiguous. The $\mathrm{P}-\mathrm{C}$ distances in $\mathbf{1}$ are in the range usually quoted for single ${ }^{64}$ and double bonds ${ }^{65}$ (1.826(31) Å and $1.674(28) \AA$, respectively), which clearly is typical for "aromatic bonds." The QTAIM descriptor of ellipticity can be interpreted as a support for the hypothesis of aromatic or conjugated $\mathrm{P}-\mathrm{C}$ bonds as well. The induced current as a magnetic criterion indicates only very weak currents on the $\mathrm{C}-\mathrm{P}-\mathrm{C}$ bridge and qualitatively agrees with the $\delta(\mathrm{A}, \mathrm{B})$ analysis in this respect. The results from the source function seem to be typical in the case of the six-membered rings. ${ }^{42,43}$ The strong influence of the heteroatoms (including the phosphorus atom) in terms of their percentage SF contribution to various reference points is striking; we take this as an indication for electron delocalization, but it is too 
early to draw conclusions regarding the amount of electron delocalization based on the SF indicator.

Nonetheless, the phosphorus atom coordinationally acts as a formal $4 \mathrm{e}^{-}$donor in metal coordination, which can be interpreted as a chemical consequence of two VSCCs in the nonbonding region ${ }^{6}$ while the sulfur atom is loath to coordinate even soft metals. ${ }^{7 d}$ Anyhow, both VSCCs at phosphorus and sulfur are attractive to positively polarized hydrogen atoms and employed in $\mathrm{C}-\mathrm{H} \cdots \mathrm{P}$ and $\mathrm{C}-\mathrm{H} \cdots \mathrm{S}$ hydrogen bonding.

The electronic situation in $\mathbf{1}$ obviously is impossible to be visualized by established canonical forms. ${ }^{66}$ Lewis formulae and VB/VSEPR rabbit-ear lone pairs serve well as tools for the prediction of molecular geometries in many cases ever since they were introduced, but they do not serve well to understand this particular case. One should keep in mind that simple models, as much as they are necessary, sometimes can obstruct our view on reality.

\section{Acknowledgements}

We kindly acknowledge funding from the DFG, especially from the Priority Programme 1178, the DNRF funded Center for Materials Crystallography (CMC) and the doctoral programme Catalysis for Sustainable Synthesis (CaSuS), provided by the state of Niedersachsen. H. F. thanks for support by the Norwegian Research Council through the CoE Centre for Theoretical and Computational Chemistry (Grant No. 179568/V30). This work has received support from the Norwegian Supercomputing Program (NOTUR) through a grant of computer time (Grant No. NN4654K).

\section{Notes and references}

1 (a) D. Kratzert, D. Leusser, J. J. Holstein, B. Dittrich, K. Abersfelder, D. Scheschkewitz and D. Stalke, Angew. Chem., Int. Ed., 2013, 52, 4478-4482; (b) H. Fliegl, S. Taubert, O. Lehtonen and D. Sundholm, Phys. Chem. Chem. Phys., 2011, 13, 20500; (c) E. Matito, J. Poater, M. Solà and P. v. R. Schleyer, in Chemical Reactivity Theory, ed. P. K. Chattaray, Taylor and Francis/CRC Press, Boca Ratón, edn, 2009, pp. 419-438; (d) P. v. R. Schleyer, Chem. Rev., $2005,105,3433$, and the whole thematic issue "Delocalization Pi and Sigma" in Chem. Rev., 2005, 105(10); (e) P. v. R. Schleyer, Chem. Rev., 2001, 101, 1115, and the whole thematic issue "Aromaticity" in Chem. Rev., 2001, 101(5).

2 (a) C. Kling, D. Leusser, T. Stey and D. Stalke, Organometallics, 2011, 30, 2461; (b) A. Murso, M. Straka, M. Kaupp, R. Bertermann and D. Stalke, Organometallics, 2005, 24, 3576; (c) S. Wingerter, M. Pfeiffer, A. Murso, C. Lustig, T. Stey, V. Chandrasekhar and D. Stalke, J. Am. Chem. Soc., 2001, 123, 1381; (d) M. Pfeiffer, T. Stey, H. Jehle, B. Klüpfel, W. Malisch, D. Stalke and V. Chandrasekhar, Chem. Commun., 2001, 337; (e) T. Kottke and D. Stalke, Chem. Ber., 1997, 130, 1365; $(f)$ A. Steiner and D. Stalke, Angew. Chem., Int. Ed. Engl., 1995, 34, 1752; $(g)$ H. Gornitzka and D. Stalke, Angew. Chem., Int. Ed. Engl., 1994, 33, 693.
3 P. Macchi, Angew. Chem., Int. Ed., 2009, 48, 5793.

4 C. B. Hübschle and B. Dittrich, J. Appl. Crystallogr., 2011, 44, 238.

5 J. W. Dube, C. L. B. Macdonald and P. J. Ragogna, Angew. Chem., Int. Ed., 2012, 52, 13026-13030.

6 J. Henn, K. Meindl, A. Oechsner, G. Schwab, T. Koritsanszky and D. Stalke, Angew. Chem., Int. Ed., 2010, 49, 2422.

7 (a) T. Stey, M. Pfeiffer, J. Henn, S. K. Pandey and D. Stalke, Chem.-Eur. J., 2007, 13, 3636; (b) T. Stey, J. Henn and D. Stalke, Chem. Commun., 2007, 413; (c) A. Steiner and D. Stalke, Organometallics, 1995, 14, 2422; (d) A. Steiner and D. Stalke, J. Chem. Soc., Chem. Commun., 1993, 444.

8 R. F. W. Bader, Oxford University Press, New York, 1st edn, 1990, p. 22.

9 (a) U. Flierler, D. Stalke and L. J. Farrugia, in Modern Charge Density Analysis, ed. C. Gatti and P. Macchi, Springer, Heidelberg, London, New York, 2012, pp. 435-467; (b) U. Flierler and D. Stalke, in Structure and Bonding, ed. D. Stalke, Springer, Berlin, New York, 2012, vol. 146, pp. 1-20; (c) U. Flierler and D. Stalke, in Structure and Bonding, ed. D. Stalke, Springer, Berlin, New York, 2012, vol. 146, pp. 75-100; (d) D. Stalke, Chem.-Eur. J., 2011, 17, 9264.

10 A. Volkov, P. Macchi, L. J. Farrugia, C. Gatti, P. R. Mallinson, T. Richter and T. Koritsanszky, XD2006, A Computer Program Package for Multipole Refinement, Topological Analysis of Charge Densities and Evaluation of Intermolecular Energies from Experimental or Theoretical Structure Factors, 2006.

11 E. Hückel, Z. Phys., 1931, 70, 204.

12 W. Kutzelnigg, J. Comput. Chem., 2007, 28, 25.

13 G. Frenking and A. Krapp, J. Comput. Chem., 2007, 28, 15.

14 (a) S. Shaik, H. S. Rzepa and R. Hoffmann, Angew. Chem., Int. Ed., 2013, 52, 3020-3033; (b) G. Frenking and M. Hermann, Angew. Chem., Int. Ed., 2013, 52, 5922-5925.

15 (a) D. Stalke, Chem. Soc. Rev., 1998, 27, 171; (b) T. Kottke and D. Stalke, J. Appl. Crystallogr., 1993, 26, 615.

16 Bruker SAINT v7.68A, Madison, WI, USA, 2009.

17 G. M. Sheldrick, SADABS 2008/2, Madison, WI, USA, 2008.

18 G. M. Sheldrick, Acta Crystallogr., Sect. A: Found. Crystallogr., 2008, 64, 112.

19 F. H. Allen, Acta Crystallogr., Sect. B: Struct. Sci., 1986, 42, 515. 20 N. K. Hansen and P. Coppens, Acta Crystallogr., Sect. A: Found. Crystallogr., 1978, 34, 909.

21 (a) P. M. Dominiak and P. Coppens, Acta Crystallogr., Sect. A: Found. Crystallogr., 2006, 62, 224; (b) A. Volkov, Y. A. Abramov and P. Coppens, Acta Crystallogr., Sect. A: Found. Crystallogr., 2001, 57, 272.

22 R. Herbst-Irmer, J. Henn, J. J. Holstein, C. B. Hübschle, B. Dittrich, D. Stern, D. Kratzert and D. Stalke, J. Phys. Chem. A, 2013, 117, 633.

23 (a) V. V. Zhurov, E. A. Zhurova and A. A. Pinkerton, J. Appl. Crystallogr., 2008, 41, 340; (b) A. Stash, DRKplot for XD and SHELX, Moscow, 2007.

24 K. Meindl and J. Henn, Acta Crystallogr., Sect. A: Found. Crystallogr., 2008, 64, 404.

25 R. F. W. Bader, R. J. Gillespie and P. J. MacDougall, J. Am. Chem. Soc., 1988, 110, 7329. 
26 R. J. Gillespie, Molecular Geometry, Reinhold Van Nostrand, London, 1972.

27 Persistence of Vision Raytracer Pty. Ltd., PoV-Ray (Version 3.7), Williamstown, Victoria, Australia, 2010.

28 (a) M. Cyrañski, T. M. Krygowski, A. R. Katritzky and P. v. R. Schleyer, J. Org. Chem., 2002, 67, 1333; (b) A. R. Katritzky, P. Barczynski, G. Musumarra, D. Pisano and M. Szafran, J. Am. Chem. Soc., 1989, 111, 7.

29 (a) P. Munshi, T. S. Thakur, T. N. G. Rowa and G. R. Desiraju, Acta Crystallogr., Sect. B: Struct. Sci., 2006, 62, 118; (b) P. Munshi and T. N. G. Row, Acta Crystallogr., Sect. B: Struct. Sci., 2006, 62, 612; (c) A. Ranganathan, G. U. Kulkarni and C. N. R. Rao, J. Mol. Struct., 2003, 656, 249; (d) S. Dahaoui, V. Pichon-Pesme, J. A. K. Howard and C. Lecomte, J. Phys. Chem. A, 1999, 103, 6240.

30 (a) G. Saleh, C. Gatti, L. L. Presti and J. Contreras-García, Chem.-Eur. J., 2012, 18, 15523; (b) J. Contreras-García, W. Yang and E. R. Johnson, J. Phys. Chem. A, 2011, 115, 12983; (c) E. R. Johnson, S. Keinan, P. Mori-Sánchez, J. Contreras-García, A. J. Cohen and W. Yang, J. Am. Chem. Soc., 2010, 132, 6498.

31 (a) G. Saleh, L. Lo Presti and C. Gatti, NCI Milano, Milan, Italy, 2012; (b) G. Saleh, C. Gatti and L. Lo Presti, Comput. Theor. Chem., 2012, 998, 148.

32 (a) H. A. Bent, Chem. Rev., 1961, 61, 275; (b) H. A. Bent, J. Chem. Educ., 1960, 37, 616.

33 A. R. Katritzky, K. Jug and D. C. Oniciu, Chem. Rev., 2001, 101, 1421.

34 (a) T. M. Krygowski, J. Chem. Inf. Comput. Sci., 1993, 33, 70, Calculated HOMA values for $\mathbf{1}$ are given in the ESI $\dagger$; (b) C. W. Bird, Tetrahedron, 1992, 48, 335.

35 (a) R. H. Mitchell, Chem. Rev., 2001, 101, 1301; (b) R. C. Haddon, V. R. Haddon and L. J. Jackman, in Top. Curr. Chem., Springer, Berlin, 1971, vol. 16, p. 2.

36 (a) P. Lazzeretti, Phys. Chem. Chem. Phys., 2004, 6, 217; (b) J. A. N. F. Gomes and R. B. Mallion, Chem. Rev., 2001, 101, 1359; (c) P. Lazzeretti, Prog. Nucl. Magn. Reson. Spectrosc., 2000, 36, 1.

37 (a) Z. Chen, C. S. Wannere, C. Corminboeuf, R. Puchta and P. v. R. Schleyer, Chem. Rev., 2005, 105, 3842; (b) P. v. R. Schleyer, C. Maerker, A. Dransfeld, H. Jiao and N. J. R. v. E. Hommes, J. Am. Chem. Soc., 1996, 118, 6317.

38 (a) R. F. W. Bader, T. S. Slee, D. Cremer and E. Kraka, J. Am. Chem. Soc., 1983, 105, 5061; (b) R. F. W. Bader, T.-H. Tang, Y. Tal and F. W. Biegler-König, J. Am. Chem. Soc., 1982, 104, 946.

39 D. Cremer, E. Kraka, T. S. Slee, R. F. W. Bader, C. D. H. Lau, T. T. Nguyen-Dang and P. J. MacDougall, J. Am. Chem. Soc., 1983, 105, 5069.

40 (a) H. Ott, U. Pieper, D. Leusser, U. Flierler, J. Henn and D. Stalke, Angew. Chem., Int. Ed., 2009, 48, 2978; (b) W. Scherer, P. Sirsch, D. Shorokhov, G. S. McGrady, S. A. Mason and M. G. Gardiner, Chem.-Eur. J., 2002, 8, 2324; (c) W. Scherer, P. Sirsch, M. Grosche, M. Spiegler, S. A. Mason and M. G. Gardiner, Chem. Commun., 2001, 2072 .
41 M. Tafipolsky, W. Scherer, K. Öfele, G. Artus, B. Pedersen, W. A. Herrmann and G. S. McGrady, J. Am. Chem. Soc., 2002, 124, 5865.

42 L. J. Farrugia and A. D. Khalaji, J. Phys. Chem. A, 2011, 115, 12512.

43 R. F. W. Bader and C. Gatti, Chem. Phys. Lett., 1998, 287, 233.

44 C. Gatti, in Structure and Bonding, ed. D. Stalke, Springer, Berlin, New York, edn, 2012, vol. 147, pp. 193-286.

45 E. Monza, C. Gatti, L. Lo Presti and E. Ortoleva, J. Phys. Chem. A, 2011, 115, 12864.

46 L. J. Farrugia and P. Macchi, J. Phys. Chem. A, 2009, 113, 10058.

47 H.-J. Werner, P. J. Knowles, G. Knizia, F. R. Manby and M. Schütz, MOLPRO, version 2010.1, A package of ab initio programs, see: http:/www.molpro.net.

48 (a) H.-J. Werner, F. R. Manby and P. J. Knowles, J. Chem. Phys., 2003, 118, 8149; (b) T. H. Dunning, J. Chem. Phys., 1989, 90, 1007.

49 P. Lazzeretti, Phys. Chem. Chem. Phys., 2004, 6, 217.

50 S. Loibl, F. R. Manby and M. Schütz, Mol. Phys., 2010, 108, 477.

51 (a) S. Taubert, D. Sundholm and J. Jusélius, J. Chem. Phys., 2011, 134, 054123; (b) J. Jusélius, D. Sundholm and J. Gauss, J. Chem. Phys., 2004, 121, 3952.

52 R. Ahlrichs, M. Bär, M. Häser, H. Horn and C. Kölmel, Chem. Phys. Lett., 1989, 162, 165.

53 (a) K. Wolinski, J. F. Hinton and P. Pulay, J. Am. Chem. Soc., 1990, 112, 8251; (b) R. Ditchfield, Mol. Phys., 1974, 27, 789; (c) H. F. Hameka, Mol. Phys., 1958, 1, 203; (d) F. London, J. Phys. Radium, 1937, 8, 397.

54 (a) A. D. Becke, J. Chem. Phys., 1993, 98, 5648; (b) C. Lee, W. Yang and R. G. Parr, Phys. Rev. B: Condens. Matter Mater. Phys., 1988, 37, 785.

55 F. Weigend and R. Ahlrichs, Phys. Chem. Chem. Phys., 2005, 7, 3297.

56 (a) M. Kaipio, M. Patzschke, H. Fliegl, F. Pichierri and D. Sundholm, J. Phys. Chem. A, 2012, 116, 10257; (b) H. Fliegl, O. Lehtonen, M. Patzschke, D. Sundholm and Y. C. Lin, Theor. Chem. Acc., 2011, 129, 701; (c) H. Fliegl, D. Sundholm and F. Pichierri, Phys. Chem. Chem. Phys., 2011, 13, 20659; (d) H. Fliegl, D. Sundholm, S. Taubert and F. Pichierri, J. Phys. Chem. A, 2010, 114, 7153; (e) S. Taubert, D. Sundholm and F. Pichierri, J. Org. Chem., 2009, 74, 6495; (f) M. P. Johansson, J. Jusélius and D. Sundholm, Angew. Chem., Int. Ed., 2005, 44, 1843; $(g)$ Y. C. Lin, J. Jusélius, D. Sundholm and J. Gauss, J. Chem. Phys., 2005, 122, 214308.

57 H. Fliegl, D. Sundholm, S. Taubert, J. Jusélius and W. Klopper, J. Phys. Chem. A, 2009, 113, 8668.

58 (a) J. A. N. F. Gomes and R. B. Mallion, Chem. Rev., 2001, 101, 1349; (b) R. Zanasi, P. Lazzeretti, M. Malagoli and F. Piccinini, J. Chem. Phys., 1995, 102, 7150.

59 (a) GIMP: GNU Image Manipulation Program, http://www. gimp.org; (b) Jmol: An open-source Java viewer for chemical structures in 3D. http://www.jmol.org.

60 MAYAVI2: 3D Scientific Data Visualization and Plotting, http://code.enthought.com/projects/mayavi/. 
61 (a) J. Poater, X. Fradera, M. Duran and M. Solà, Chem.-Eur. J., 2003, 9, 400; (b) X. Fradera, M. A. Austen and R. F. W. Bader, J. Phys. Chem. A, 1999, 103, 304.

62 T. A. Keith, AIMAll Version 11.10.16, (aim.tkgristmill.com), 2012.

63 (a) F. Feixas, E. Matito, M. Duran, J. Poater and M. Solà, Theor. Chem. Acc., 2011, 128, 419; (b) F. Feixas, E. Matito, M. Solà and J. Poater, Phys. Chem. Chem. Phys., 2010, 12, 7126.

64 All P/C bond distances deposited in the Cambridge Structural Database that were classified as "single bond." A total number of 467284 distances was included in the statistics.
65 All P/C bond distances deposited in the Cambridge Structural Database that were classified as "double bond." The phosphorus atom was limited to a maximum number of three bonding partners in order to avoid bias by ylidic bonds. A second maximum in the resulting distance distribution was ignored because a survey in a random sample of corresponding structures indicated that the maximum was created by ylidic $\mathrm{P}-\mathrm{C}$ bonds with ambiguous bond order. A total number of 501 distances was eventually included in the statistics.

66 (a) P. P. Power, Nature, 2010, 463, 171; (b) J. Kapp, C. Schade, A. M. El-Nahasa and P. v. R. Schleyer, Angew. Chem., Int. Ed. Engl., 1996, 35, 2373-2376. 